\title{
Study of Electrokinetic Properties of Magnetite - Silica Core - Shell Nanoparticles
}

\author{
YU. A. UTKIN ${ }^{1}$, MingGONG SHA ${ }^{2}$, \\ ${ }^{1}$ Moscow Aviation Institute (National Research University), \\ Moscow, Volokolamskoe shosse, 4, 125993, \\ RUSSIA \\ ${ }^{2}$ School of Civil Aviation, Northwestern Polytechnical University (NPU), \\ Xi'an Shaanxi, 127 West Youyi Road, Beilin District, 710072, \\ CHINA
}

\begin{abstract}
In this work, the electrokinetic properties of $\mathrm{Fe}_{3} \mathrm{O}_{4}$ nanoparticles modified with various alkoxysilanes (tetraethoxysilane and 3-aminopropyltriethoxysilane) in various media were investigated. The determined values of the zeta potential of the $\mathrm{Fe}_{3} \mathrm{O}_{4} / \mathrm{SiO}_{2}$ samples indicate the complete coverage of nanoparticles with a tetraethoxysilane shell, as well as in the case of the $\mathrm{Fe}_{3} \mathrm{O}_{4}$ /aminopropyltriethoxysilane. The data obtained on the zeta-potentials of modified nanoparticles with various ligands make it possible to predict the efficiency of subsequent functionalization by target molecules.

A decisive role in the study of surface properties is played by cleaning from low molecular weight impurities that can screen the surface of nanoparticles or bind with an indifferent electrolyte. Thus, dispersion on a magnetic stirrer leads to an increase in the sorption capacity of the sample in comparison with ultrasonic dispersion, which causes irreversible destruction of the core- shell nanoparticle structure due to an increase in temperature and pressure in the cavities. This opens the prospective for practical application of modified nanoparticles for creation of tailored composite materials.
\end{abstract}

Keywords-Nanoparticles, composites, magnetite, silica.

Received: April 27, 2021. Revised: September 3, 2021. Accepted: September 14, 2021. Published: September 25, 2021.

\section{Introduction}

$\mathrm{I}_{\mathrm{o}}$ $\mathrm{N}$ order to solve possible problems with the introduction of magnetite nanoparticles into a living organism, such as instability under physiological conditions [1]-[12], the formation of free radicals dangerous for the body, as well as insufficient strong bond with ligands during targeted drug delivery, nanoparticles cover a protective a shell that should ensure their stability, reduce toxicity to a minimum, and have the ability to form strong bonds with various types of ligands that are used to functionalize the surface of nanoparticles [13][25]. Serious concern is also caused by the behavior of materials based on $\mathrm{Fe}_{3} \mathrm{O}_{4}$ nanoparticles, which are widely used as detoxicants in the restoration of the environment, in particular, for the removal of chlorine-containing compounds, organic dyes, heavy metals from technogenic and natural aqueous media. $\mathrm{Fe}_{3} \mathrm{O}_{4}$ nanoparticles are subject to oxidation in air and easily aggregate in aqueous systems. The necessary stabilization of iron oxide nanoparticles by surface modification should pursue a double goal: control of the size and polydispersity during synthesis and stabilization of nanoparticles against aggregation after synthesis [26]-[35]. Modification of nanoparticles is carried out using various inorganic or organic compounds by their non-covalent or covalent immobilization on the surface of iron oxide nanoparticles, which leads to a change in their primary properties and allows expanding the areas of their potential application [36]-[45]. There is a wide range of substances capable of forming a protective shell on the surface of magnetite nanoparticles; among them, alkoxysilanes are of interest as inert, biocompatible, and functional inorganic ligands.

Modern composites have not only a wide range of physical and mechanical properties, but are also capable of directionally changing them, for example, increasing fracture toughness, regulating rigidity, strength, and other properties. These possibilities are expanded when fibers of different nature and geometry are used in composites, i.e., when creating hybrid composites. In addition, these materials are characterized by the appearance of a synergistic effect (coordinated joint action of several factors in one direction) [45]-[75].

The properties of the interface or interfacial zone, first of all, the adhesive interaction between the fiber and the matrix, determine the level of properties of composites and their retention during operation. Local stresses in the composite reach their maximum values just near or directly at the interface, where material destruction usually begins. The interface must have certain properties to ensure efficient 
transfer of the mechanical load from the matrix to the fiber. The adhesion bond at the interface should not be destroyed under the action of thermal and shrinkage stresses arising from the difference in the temperature coefficients of linear expansion of the matrix and fiber or as a result of chemical shrinkage of the binder during its curing.

When creating nanocomposites, the key tasks are the development of efficient, reliable, and affordable production technologies for mass production, which make it possible to obtain materials with stable characteristics. The hand lay technique, also called wet lay, is the simplest and most widely used process for producing flat reinforced composites. The process consists of laying layers of a polymer in successive layering using an epoxy matrix. Wet-laying is a molding process that combines layers of reinforced carbon fiber with epoxy to create a high-quality laminate. Before starting the installation process, you must prepare the appropriate form. This preparation consists of cleaning the table and applying a release agent to the surface. The manual laying process can be divided into four main steps: mold preparation, epoxy coating, laying and curing. Form preparation is one of the most important steps in the installation process. This process requires dry reinforcement layers and the application of a wet epoxy matrix. They are connected together - reinforcing material, impregnated with a matrix

Coatings on nano and micro-sized particles can serve for many purposes. First of all, modification of the surface with coatings makes it possible to make the particles compatible with various matrixes [14]-[30]. For medical purposes, the biocompatibility with the environments of a living organism is of crucial importance. It is equally important that coatings can significantly enhance or decrease the sorption properties of magnetically controlled sorbents. This provides prerequisites for the creation of magnetically controlled particles with specific sorption properties. It is also known that the coatings prevent the core from leaching out. The presence of a coating also often facilitates the stabilization of particles in an environment with an alkaline $\mathrm{pH}$ or significant salt concentration. For example, the isoelectric point of $\mathrm{SiO}_{2}$ is reached at $\mathrm{pH} 2-3$. Therefore, the particles coated with silica are negatively charged at the $\mathrm{pH}$ of the blood, which causes electrostatic repulsion, which avoids the formation of clumps.

The ability of the adsorbent to absorb the adsorbate is characterized by the amount of adsorption. The amount of adsorption is the excess mass of the adsorbate in the boundary layer over its mass in an equal volume of the environment, referred to the unit surface of the adsorbent.

Sometimes the adsorption value is expressed in moles of adsorbate per $1 \mathrm{~m}^{2}$ (or $1 \mathrm{~cm}^{2}$ ) of the adsorbent surface. Since quite often the surface of the adsorbent is unknown, the value of adsorption is expressed in moles of adsorbate per $1 \mathrm{~g}$ of adsorbent (mol/g). It is customary to evaluate the process of toxin sorption by the adsorbing surface using the curves of Langmuir sorption isotherms.

Silanol binding agents are applied directly to the surface of
$\mathrm{Fe}_{3} \mathrm{O}_{4}$ nanoparticles by copolymerization of monomers or by direct silanization. The developed surface of nanoparticles leads to a high density of surface functional groups [48]-[57], which can fix a large number of biologically active substances [32]. The most common way to obtain $\mathrm{Fe}_{3} \mathrm{O}_{4} / \mathrm{SiO}_{2}$ with a coreshell structure is the sol-gel method (Stober method), which consists in hydrolysis and polycondensation under alkaline conditions in ethanol [33].

In this regard, in this work, we performed a comparative analysis of the microstructure of magnetite nanoparticles synthesized by various methods before and after their modification with 3-aminopropyltriethoxysilane under various reaction conditions (in argon and during oxidation).

Analyzing the works where the authors provide data on the electrokinetic properties of magnetite nanoparticles coated with silanes, it can be noted that under various conditions for the preparation of nanoparticles (different sample preparation, temperature and time of preparation, drying conditions), the authors obtained samples identical in structure and composition according to the IR data and the method of electrophoretic light scattering. However, the lack of uniformity in the characteristic absorption bands and the position of isoelectric points for the same samples does not make it possible to correctly evaluate the physicochemical data and the success of the preparation.

The aim of this work was to study the electrokinetic properties of $\mathrm{Fe}_{3} \mathrm{O}_{4}$ nanoparticles upon their modification with various alkoxysilanes (tetraethoxysilane and 3aminopropyltriethoxysilane) in various media, and also to determine the zeta potential and hydrodynamic diameter of the obtained nanocomposites by the method of dynamic and electrokinetic light scattering.

\section{Study of the electrokinetic properties of nanoparticles}

An examination of the data obtained makes it possible to show that systematic changes are observed in the experimental spectra, which are the same at different temperatures. Moreover, when passing from a sample of native particles to a sample of coated particles, they are less than from a sample of coated particles to a sample of oxidized particles. Thus, the treatment of the initial sample of magnetite with aminopropyltriethoxysilane (APTES) leads to a narrowing of the external profile of the relaxation sextet, apparently due to the sharpening of the internal sextets. The processing of a sample of APTES coated particles with nitric acid caused the removal of components from the right side of the spectra, and the appearance of components in the left side of the spectrum, i.e. in fact, we are talking about a shift of some sextet to the region of low isomeric shifts, i.e. oxidation of iron.

Electrokinetic measurements provide independent information about the electric double layer of charged particles [62]-[66]. The measured electrophoretic mobility of particles can be converted to an electrokinetic (zeta) potential according to the equation: 


$$
\xi=\frac{\mu 3 \eta}{2 \varepsilon}
$$

where $\xi$ - zeta potential, $\mu$ - electrophoretic mobility, $\eta-$ medium viscosity, $\varepsilon$ - the dielectric constant.

The value of electrophoretic mobility, measured in a dispersion of metal oxides, changes at a certain $\mathrm{pH}$ value $(\mathrm{pH}$ of the isoelectric point, IEP), at which amphoteric particles do not have an excess charge.

The zeta potential determined for the $\mathrm{Fe}_{3} \mathrm{O}_{4}, \mathrm{Fe}_{3} \mathrm{O}_{4} /$ APTES (A), $\mathrm{Fe}_{3} \mathrm{O}_{4}$ /APTES (B), and $\mathrm{Fe}_{3} \mathrm{O}_{4}$ /TEOS samples is shown in Fig. 1 and found at $\mathrm{pH}=2.8, \mathrm{pH}=7.1$ and $\mathrm{pH}=6.6$, respectively. The $\mathrm{Fe}_{3} \mathrm{O}_{4} /$ TEOS sample has a negative charge in the range of $\mathrm{pH}=3-10$. due to the presence on the surface of $\mathrm{Si}-\mathrm{OH}$ groups characteristic of tetraethoxysilane (TEOS). The shift of the isoelectric point of magnetite from $\mathrm{pH}=6.3$ to $\mathrm{pH}$ $=2.8$ indicates complete coverage of the magnetite surface with tetraethoxysilane. The presence of amino groups on the surface should shift the IEP towards higher $\mathrm{pH}$ values. The IEP value for $\mathrm{Fe}_{3} \mathrm{O}_{4}$ /APTES (A) in the region of $\sim \mathrm{pH} 7$ may be due to the presence of protonated amino groups on the $\mathrm{SiO}_{2}$ surface or their small presence or absence. This is consistent with the position of the zeta potential curve, according to which in the alkaline region on the surface of $\mathrm{Fe}_{3} \mathrm{O}_{4}$ /APTES (A) there are fewer negative charges than on the surface of $\mathrm{Fe}_{3} \mathrm{O}_{4}$ and $\mathrm{Fe}_{3} \mathrm{O}_{4}$ /APTES (B). Reactions of surface centers $\mathrm{Fe}_{3} \mathrm{O}_{4}-\mathrm{Si}-\mathrm{O}-\mathrm{NH}_{2}$ with $\mathrm{H}+$ and $\mathrm{OH}$ ions lead to the formation of positive $\left(\mathrm{Fe}-\mathrm{Si}-\mathrm{O}-\mathrm{NH}_{3}{ }^{+}\right)$and uncharged surfaces $\left(\mathrm{Fe}-\mathrm{Si}-\mathrm{NH}_{2}\right)$.

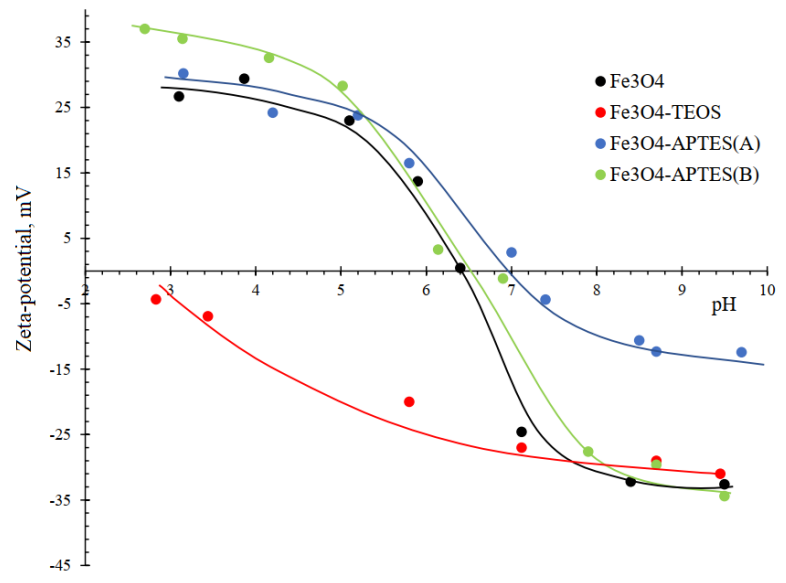

Fig. 1 dependence of the $\zeta$-potential of $\mathrm{Fe}_{3} \mathrm{O}_{4}, \mathrm{Fe}_{3} \mathrm{O}_{4} / \mathrm{TEOS}$, $\mathrm{Fe}_{3} \mathrm{O}_{4} / \mathrm{APTES}(\mathrm{A})$ and $\mathrm{Fe}_{3} \mathrm{O}_{4} /$ APTES (B) nanoparticles on $\mathrm{pH}(0,0$ $\mathrm{KCl})$.

The value of IEP $\mathrm{Fe}_{3} \mathrm{O}_{4}$ /APTES (B) near $\mathrm{pH} 6$ is explained by the presence of protonated amino groups on the $\mathrm{SiO}_{2}$ surface. However, in the alkaline region on the surface of $\mathrm{Fe}_{3} \mathrm{O}_{4}$ /APTES (B) there are more negative charges than on the surface of $\mathrm{Fe}_{3} \mathrm{O}_{4} /$ APTES (A), which may indicate a larger number of alcohol $\mathrm{OH}$ groups on the surface of nanoparticles. In the case of [65], the zeta potential is $+30 \mathrm{mV}$ over the entire $\mathrm{pH}$ range, which is an indicator of the stability of nanoparticles coated with APTES and may also indicate the presence of $\mathrm{NH}_{3}$
+ on the surface of nanoparticles. APTES has IEP at pH 10,05. The difference in the data for the zeta potential for $\mathrm{Fe}_{3} \mathrm{O}_{4}$ /APTES samples in different works indicates the dependence of the zeta potential value on the method and conditions of synthesis, the ratio of components and purification of preparations, despite the same component composition of nanoparticles.

Samples $\mathrm{Fe}_{3} \mathrm{O}_{4}$ and $\mathrm{Fe}_{3} \mathrm{O}_{4}$ /APTES (B) are unstable in a narrow range of $\mathrm{pH}=5.6-7$, however, in the range of $\mathrm{pH} 3-5.6$ and above 7 , the $\xi$-potential is $\pm 30 \mathrm{mV}$ and the system remains stable. At the same time, the $\mathrm{Fe}_{3} \mathrm{O}_{4}$ /APTES (A) sample obtained in an inert medium is stable only in a narrow $\mathrm{pH}$ range of 3-5 and then, with an increase in $\mathrm{pH}$, the $\xi$ potential begins to decrease, not exceeding $-10 \mathrm{mV}$, and the system loses stability. The $\mathrm{Fe}_{3} \mathrm{O}_{4} /$ TEOS sample is stable in a wide range of $\mathrm{pH}=6-10$ and loses its stability in a strongly acidic medium in the region of the isoelectric point. When assessing the surface charge of the surface of modified magnetite samples, it was revealed that not only the synthesis conditions in various media (inert - in argon and not inert with air access), but also the subsequent dispersion treatment of the samples to obtain suspended particles affect the value of the zeta potential.

Impact has been identified:

- Dialysis. After dialysis, the IEP of the $\mathrm{Fe}_{3} \mathrm{O}_{4}$ /APTES (ADUs) sample shifts from $\mathrm{pH}=7.2$ for $\mathrm{Fe}_{3} \mathrm{O}_{4} /$ APTES (A) to $\mathrm{pH}$ $=6.2$

- Influence of the method of dispersion. For the $\mathrm{Fe}_{3} \mathrm{O}_{4}$ /APTES (A-DM) sample, after stirring on a magnetic stirrer, the IEP value shifts to the acidic region to $\mathrm{pH} 6.6$, and after ultrasound - to $\mathrm{pH} 6.2\left(\mathrm{Fe}_{3} \mathrm{O}_{4} /\right.$ APTES (A-D-Us) sample (Fig. 2).

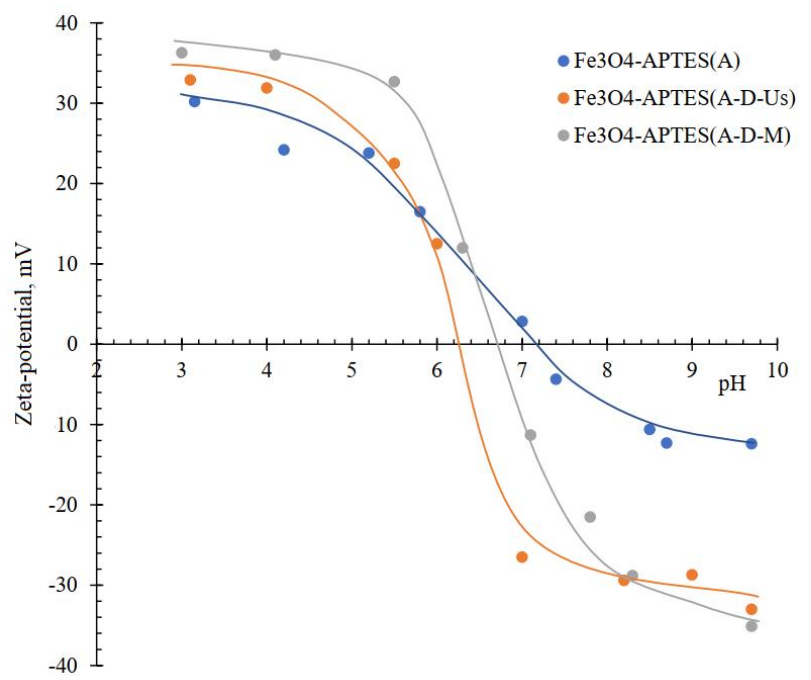

Fig. 2 dependence of the $\zeta$-potential of $\mathrm{Fe}_{3} \mathrm{O}_{4} / \mathrm{APTES}(\mathrm{A})$, $\mathrm{Fe}_{3} \mathrm{O}_{4} / \mathrm{APTES}$ (A-D-Us) and $\mathrm{Fe}_{3} \mathrm{O}_{4} / \mathrm{APTES}$ (A-D-M) nanoparticles on $\mathrm{pH}(0,01 \mathrm{M} \mathrm{KCl})$ after dialysis.

The average hydrodynamic diameter (Dh) of nanoparticles depends on the $\mathrm{pH}$ value. The $\mathrm{pH}$ at which NPs have the maximum size fully correlates with the IEP $\mathrm{pH}$. 


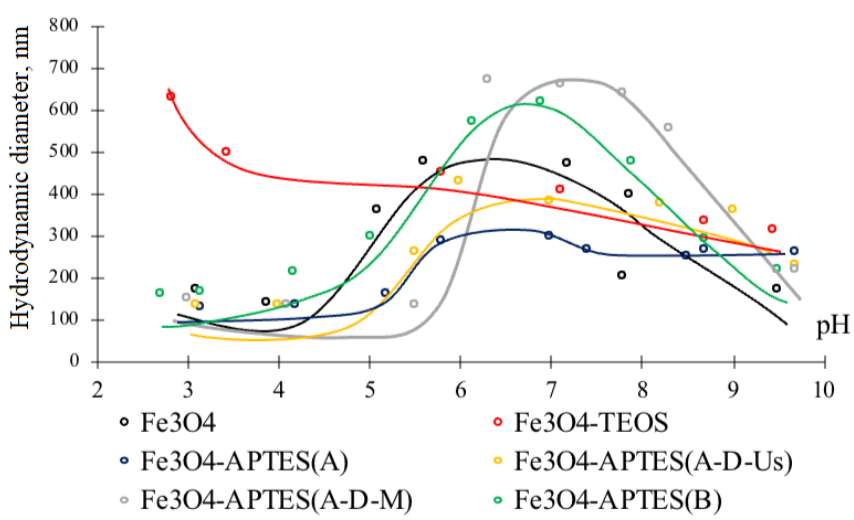

Fig. 3 change in the average hydrodynamic diameter of nanoparticles at different $\mathrm{pH}$ and modification agent.

In the range of $\mathrm{pH}>9$, the average hydrodynamic size is 100-400 nm for all samples; at $\mathrm{pH}<5$, the values remain the same except for TEOS, for which the size is $450-650 \mathrm{~nm}$. An increase in the hydrodynamic diameter of $\mathrm{Fe}_{3} \mathrm{O}_{4} / \mathrm{TEOS}$ particles in the range of $\mathrm{pH}=3$ is due to the proximity to the isoelectric point and aggregation of nanoparticles. In addition, the difference in values between the $\mathrm{Fe}_{3} \mathrm{O}_{4} / \mathrm{TEOS}$ sample and the rest of the samples outside the isoelectric point (about 450 $\mathrm{nm}$ for $\mathrm{Fe}_{3} \mathrm{O}_{4} / \mathrm{TEOS}$ and about $200 \mathrm{~nm}$ for the rest of the samples) is probably due to the difference in the time of sample preparation and measurement of the hydrodynamic diameter. This means that the effective hydrodynamic diameter of the modified nanoparticles is strongly dependent on the modification agent and the way of synthesis.

\section{Conclusion}

A decisive role in the study of surface properties is played by cleaning from low molecular weight impurities that can screen the surface of nanoparticles or bind with an indifferent electrolyte. The stage of dispersive post-preparation of samples is also important for the correct determination of the sorption capacity and hydrodynamic diameter of particles as it was clearly seen from the electrokinetic measurements. Thus, dispersion on a magnetic stirrer leads to an increase in the sorption capacity of the sample in comparison with ultrasonic dispersion, which causes irreversible destruction of the coreshell nanoparticle structure due to an increase in temperature and pressure in the cavities.

\section{References}

[1] L. N. Rabinskiy, S. A. Sitnikov, "Development of technologies for obtaining composite material based on silicone binder for its further use in space electric rocket engines," Periodico Tche Quimica, 15 (Special Issue 1), pp. 390-395, 2018.

[2] P. F. Pronina, O. V. Tushavina, E. I. Starovoitov, "Study of the radiation situation in moscow by investigating elastoplastic bodies in a neutron flux taking into account thermal effects," Periodico Tche Quimica, 17(35), pp. 753-764, 2020.

[3] O. A. Butusova, "Surface Modification of Titanium Dioxide Microparticles Under Ultrasonic Treatment," International Journal of Pharmaceutical Research, vol. 12, i. 4, pp. 2292-2296, 2020.

[4] O. A. Butusova. "Adsorption Behaviour of Ethylhydroxyethyl Cellulose on the Surface of Microparticles of Titanium and Ferrous Oxides," International Journal of Pharmaceutical Research, vol. 12, Supplementary Issue 2, pp. 1156-1159, 2020.

[5] A. N. Tarasova, "Effect of Vibration on Physical Properties of Polymeric Latexes," International Journal of Pharmaceutical Research, vol. 12, Supplementary Issue 2, pp. 1173-1180, 2020.

[6] V. F. Formalev, S. A. Kolesnik, B. A. Garibyan, "Mathematical modeling of heat transfer in anisotropic plate with internal sinks," AIP Conference Proceedings, 2181, 020003, 2019.

[7] O. A. Pashkov, "Influence of Polymer Coatings on the Mechanical Properties of Steel Samples in Tensile and Bending Tests," Turkish Journal of Computer and Mathematics Education (TURCOMAT), vol. 12, no. 5, pp. 542-548, 2021.

[8] O. A. Pashkov, "Investigation of the Effect of Steel Plate Size and Elevated Temperature on Critical Load in Stability Tests," Turkish Journal of Computer and Mathematics Education (TURCOMAT), vol. 12, no. 10, pp. 1657-1663, 2021.

[9] Y. Sun, O. V. Egorova, E. L. Kuznetsova, "Identification of the front angle of a plane acoustic oblique pressure wave on convex surfaces with the use of analytical solution," Journal of the Balkan Tribological Association, 27(2), pp. 189-197, 2021.

[10] V. F. Formalev, S. A. Kolesnik, B. A. Garibyan, "Heat transfer with absorption in anisotropic thermal protection of high-temperature products," Herald of the Bauman Moscow State Technical University, Series Natural Sciences, (5), pp. 35-49, 2021.

[11] S. A. Kolesnik, N. A. Bulychev, "Numerical analytic method for solving the inverse coefficient problem of heat conduction in anisotropic half-space," Journal of Physics: Conference Series, 1474(1), 012024, 2020.

[12] O. A. Pashkov, "Theoretical calculation of the thickness of interphase zones in the Al-Al2O3 composite," to be published.

[13] O. A. Pashkov, "Theoretical calculation of the thickness of interphase zones in the Al-Al2O3 composite," Turkish Journal of Computer and Mathematics Education (TURCOMAT), vol. 12, no. 10, pp. 1672-1677, 2021.

[14] N. A. Kucheva, V. Kohlert, "Analytical solution of the problem of thermoelasticity for a plate heated by a source with a constant heat supply on one surface," Turkish Journal of Computer and Mathematics Education (TURCOMAT), vol. 12, no. 10, pp. 1622-1633, 2021.

[15] V. F. Formalev, N. A. Bulychev, S. A. Kolesnik, M. A. Kazaryan, "Thermal state of the package of cooled gasdynamic microlasers," Proceedings of SPIE - The 
International Society for Optical Engineering, 11322, article number 113221B, 2019.

[16] V. F. Formalev, S. A. Kolesnik, B. A. Garibyan, "Analytical solution of the problem of conjugate heat transfer between a gasdynamic boundary layer and anisotropic strip," Herald of the Bauman Moscow State Technical University, Series Natural Sciences, 5(92), pp. 44-59, 2020.

[17] Y. Sun, S. A. Kolesnik, E. L. Kuznetsova, "Mathematical modeling of coupled heat transfer on cooled gas turbine blades," INCAS Bulletin, 12(Special Issue), pp. 193-200, 2020.

[18] I. Kurchatov, N. Bulychev, S. Kolesnik, E. Muravev, "Application of the direct matrix analysis method for calculating the parameters of the luminescence spectra of the iron ion in zinc sulfide crystals," AIP Conference Proceedings, 2181, 020015, 2019.

[19] O. A. Butusova, "Stabilization of Carbon Microparticles by High-Molecular Surfactants," International Journal of Pharmaceutical Research, vol. 12, Supplementary Issue 2, pp. 1147-1151, 2020.

[20]A. N. Tarasova, "Effect of Reagent Concentrations on Equilibria in Water-Soluble Complexes," International Journal of Pharmaceutical Research, vol. 12, Supplementary Issue 2, pp. 1169-1172, 2020.

[21] B. A. Antufev, E. L. Kuznetsova, L. N. Rabinskiy, O. V. Tushavina, "Investigation of a complex stress-strain state of a cylindrical shell with a dynamically collapsing internal elastic base under the influence of temperature fields of various physical nature," Asia Life Sciences, (2), pp. 689-696, 2019.

[22] B. A. Antufev, E. L. Kuznetsova, L. N. Rabinskiy, O. V. Tushavina, "Complex stressed deformed state of a cylindrical shell with a dynamically destructive internal elastic base under the action of temperature fields of various physical nature," Asia Life Sciences, (2), pp. 775$782,2019$.

[23] L. N. Rabinskiy, O. V. Tushavina, "Problems of land reclamation and heat protection of biological objects against contamination by the aviation and rocket launch site," Journal of Environmental Management and Tourism, 10(5), pp. 967-973, 2019.

[24] A. N. Astapov, I. P. Lifanov, L. N. Rabinskiy, "Perspective Heat-Resistant Coating for Protection of $\mathrm{Cf} / \mathrm{SiC}$ Composites in Air Plasma Hypersonic Flow," High Temperature, 57(5), pp. 744-752, 2019.

[25] V. N. Dobryanskiy, L. N. Rabinskiy, O. V. Tushavina, "Validation of methodology for modeling effects of loss of stability in thin-walled parts manufactured using SLM technology," Periodico Tche Quimica, 16(33), pp. 650656, 2019.

[26] O. A. Pashkov, "Experimental and Theoretical Study of Mechanical Properties of Matrix Composite Materials," Turkish Journal of Computer and Mathematics Education (TURCOMAT), vol. 12, no. 10, pp. 1678-1684, 2021.

[27] O. A. Butusova, "Vinyl Ether Copolymers as Stabilizers of Carbon Black Suspensions," International Journal of
Pharmaceutical Research, vol. 12, Supplementary Issue 2, pp. 1152-1155, 2020.

[28]A. N. Tarasova, "Vibration-based Method for Mechanochemical Coating Metallic Surfaces," International Journal of Pharmaceutical Research, vol. 12, Supplementary Issue 2, pp. 1160-1168, 2020.

[29] N. A. Kucheva, V. Kohlert, "Mathematical modeling methods for estimation the thermophysical properties of heat-protective composite materials," Turkish Journal of Computer and Mathematics Education (TURCOMAT), vol. 12, no. 10, pp. 1606-1612, 2021.

[30] I. P. Lifanov, A. N. Astapov, V. S. Terentieva, "Deposition of heat-resistant coatings based on the $\mathrm{ZrSi} 2-$ MoSi2-ZrB2 system for protection of non-metallic composite materials in high-speed high-enthalpy gas flows," Journal of Physics: Conference Series, vol. 1713, no. 1, pp. 012025, 2020.

[31] I. P. Lifanov, A. A. Yurishcheva, A. N. Astapov, "Hightemperature protective coatings on carbon composites," Russian Engineering Research, vol. 39, no. 9, pp. 804 808, 2019.

[32] A. N. Astapov, I. P. Lifanov, M. V. Prokofiev, "Hightemperature interaction in the $\mathrm{ZrSi} 2-\mathrm{ZrSiO} 4$ system and its mechanism," Russian Metallurgy (Metally), no. 6, pp. 640 - 646, 2019.

[33]N. A. Kucheva, "Investigation of the mechanical properties of heat-protective highly porous composite materials using the effective medium model," Turkish Journal of Computer and Mathematics Education (TURCOMAT), vol. 12, no. 10, pp. 1613-1621, 2021.

[34] O. A. Butusova, "Design and Properties of Magnetically Controlled Sorbents," Turkish Journal of Computer and Mathematics Education (TURCOMAT), vol. 12, no. 5, pp. 515-519, 2021.

[35] O. A. Butusova, "Application of Magnetically Controlled Sorbents for Detoxication," Turkish Journal of Computer and Mathematics Education (TURCOMAT), vol. 12, no. 5, pp. 520-524, 2021.

[36] M. O. Kaptakov, "Effect of Thin Polymer Layers on Mechanical Properties of Metal Surfaces," Turkish Journal of Computer and Mathematics Education (TURCOMAT), vol. 12, no. 5, pp. 525-529, 2021.

[37] B. A. Garibyan, "Determination of the Elastic Modulus of the Coating Using a Spherical Indenter," Turkish Journal of Computer and Mathematics Education (TURCOMAT), vol. 12, no. 10, pp. 1594-1600, 2021.

[38] M. O. Kaptakov, "Modelling of Mechanical Properties of Metal Plates with Polymer Coatings," Turkish Journal of Computer and Mathematics Education (TURCOMAT), vol. 12, no. 5, pp. 530-534, 2021.

[39] B. A. Garibyan, "Theoretical Estimations of Influence of Polymer Coatings on the Elastic Modulus and Ultimate Strength of Steel Samples," Turkish Journal of Computer and Mathematics Education (TURCOMAT), vol. 12, no. 10, pp. 1651-1656, 2021.

[40] M. O. Kaptakov, "Investigation of Effective Mechanical Characteristics of Nanomodified Carbon-Epoxide Composite by Numerical and Analytical Methods," 
Turkish Journal of Computer and Mathematics Education (TURCOMAT), vol. 12, no. 5, pp. 535-541, 2021.

[41]M. O. Kaptakov, "Obtaining of Carbon Fibers Based Composite Materials and Study of Their Mechanical Properties," Turkish Journal of Computer and Mathematics Education (TURCOMAT), vol. 12, no. 10, pp. 1601-1605, 2021.

[42] A. V. Babaytsev, L. N. Rabinskiy, K. T. Aung, "Investigation of the contact zone of a cylindrical shell located between two parallel rigid plates with a gap," INCAS Bulletin, 12(Special Issue), pp. 43-52, 2020.

[43] V. G, Dmitriev, O. V. Egorova, E. I. Starovoitov, "Particularities of mathematical modeling of deformation processes for arched and panel designs of composites with large displacements and rotation angles," INCAS Bulletin, 12(Special Issue), pp. 53-66, 2020.

[44] O. V. Egorova, E. I. Starovoitov, "Non-stationary diffraction problem of a plane oblique pressure wave on the shell in the form of a hyperbolic cylinder taking into account the dissipation effect," INCAS Bulletin, 12(Special Issue), pp. 67-77, 2020.

[45]O. V. Tushavina, "Coupled heat transfer between a viscous shock gasdynamic layer and a transversely streamlined anisotropic half-space," INCAS Bulletin, 12 (Special Issue), pp. 211-220, 2020.

[46] Yu. V. Ioni, A. Ethiraj, "New Tailor-Made Polymer Stabilizers for Aqueous Dispersions of Hydrophobic Carbon Nanoparticles," International Journal of Pharmaceutical Research, vol. 12, i. 4, pp. 3443-3446, 2020.

[47] Yu. V. Ioni, "Nanoparticles of noble metals on the surface of graphene flakes," Periodico Tche Quimica, vol. 17, no. 36, pp. 1199-1211, 2020.

[48] M. O. Kaptakov, "Catalytic Desulfuration of Oil Products under Ultrasonic Treatment," International Journal of Pharmaceutical Research, vol. 12, Supplementary Issue 2, pp. 1838-1843, 2020.

[49] B. A. Garibyan, "Enhancement of Mechanical Properties of Inorganic Glass under Ultrasonic Treatment," International Journal of Pharmaceutical Research, vol. 12, Supplementary Issue 2, pp. 1829-1832, 2020.

[50]M. O. Kaptakov, "Enhancement of Quality of Oil Products under Ultrasonic Treatment," International Journal of Pharmaceutical Research, vol. 12, Supplementary Issue 2, pp. 1851-1855, 2020.

[51]B. A. Garibyan, "Mechanical Properties of Electroconductive Ceramics," International Journal of Pharmaceutical Research, vol. 12, Supplementary Issue 2, pp. 1825-1828, 2020.

[52]M. O. Kaptakov, "Effect of Ultrasonic Treatment on Stability of $\mathrm{TiO}_{2}$ Aqueous Dispersions in Presence of Water-Soluble Polymers," International Journal of Pharmaceutical Research, vol. 12, Supplementary Issue 2, pp. 1821-1824, 2020.

[53] Yu. V. Ioni, "Synthesis of Metal Oxide Nanoparticles and Formation of Nanostructured Layers on Surfaces under Ultrasonic Vibrations," International Journal of
Pharmaceutical Research, vol. 12, i. 4, pp. 3432-3435, 2020.

[54] G. A. Kalugina, A. V. Ryapukhin, "Impact of the 2020 Pandemic on Russian Aviation," Russian Engineering Research, vol. 41. no. 7, pp. 627-630, 2021.

[55]R. N. Zaripov, I. M. Murakaev, A. V. Ryapukhin, "Development of the Organization's Key Performance Indicators System in Order to Improve the Effectiveness of Its Human Capital and Risk Management," TEM Journal, vol. 10, no. 1, pp. 298-302, 2021.

[56] A. A. Kalugin, G. A. Kalugina, A. V. Ryapukhin, "Informational Support for the Sale of Passenger Aircraft," Russian Engineering Research, vol. 41, no. 2, pp. 183-187, 2021.

[57]R. N. Zaripov, I. M. Murakaev, S. V. Novikov, A. V. Ryapukhin, "Corporate Structure for Innovative Enterprises," Russian Engineering Research, vol. 40, no. 2, pp. 137-139, 2020.

[58]N. A. Bulychev, E. L. Kuznetsova, "Ultrasonic Application of Nanostructured Coatings on Metals," Russian Engineering Research, 39 (9), pp. 809-812, 2019.

[59] N. A. Bulychev, V. V. Bodryshev, L. N. Rabinskiy, "Analysis of geometric characteristics of two-phase polymer-solvent systems during the separation of solutions according to the intensity of the image of micrographs," Periodico Tche Quimica, 16(32), pp. 551559, 2019.

[60]N. A. Bulychev, A. V. Ivanov, "Effect of vibration on structure and properties of polymeric membranes," International Journal of Nanotechnology, vol. 16, nos. 6/7/8/9/10, pp. $334-343,2019$.

[61] N. A. Bulychev, A. V. Ivanov, "Nanostructure of OrganicInorganic Composite Materials Based on Polymer Hydrogels," International Journal of Nanotechnology, vol. 16, nos. 6/7/8/9/10, pp. $344-355,2019$.

[62] N. A. Bulychev, A. V. Ivanov, "Study of Nanostructure of Polymer Adsorption Layers on the Particles Surface of Titanium Dioxide," International Journal of Nanotechnology, vol. 16, nos. 6/7/8/9/10, pp. $356-365$, 2019.

[63] N. A. Bulychev, L. N. Rabinskiy, O. V. Tushavina, "Effect of intense mechanical vibration of ultrasonic frequency on thermal unstable low-temperature plasma," Nanoscience and Technology: An International Journal, 11 (1), pp. 15-21, 2020.

[64]N. A. Bulychev, L. N. Rabinskiy, "Ceramic Nanostructures Obtained by Acoustoplasma Technique," Nanoscience and Technology: An International Journal, 10 (3), pp. 279-286, 2019.

[65] Yu. V. Ioni, A. Ethiraj, "Study of Microparticles Surface Modification by Electrokinetic Potential Measuring," International Journal of Pharmaceutical Research, vol. 12, i. 4, pp. 3436-3439, 2020.

[66] Yu. V. Ioni, "Effect of Ultrasonic Treatment on Properties of Aqueous Dispersions of Inorganic and Organic Particles in Presence of Water-Soluble Polymers," International Journal of Pharmaceutical Research, vol. 12, i. 4, pp. 3440-3442, 2020. 
[67] S. Vakhneev, E. Starovoitov, "Damping of circular composite viscoelastic plate vibration under neutron irradiation," Journal of Applied Engineering Science, 18(4), pp. 699-704, 2020.

[68] V. A. Pogodin, L. N. Rabinskii, S. A. Sitnikov, "3D Printing of Components for the Gas-Discharge Chamber of Electric Rocket Engines," Russian Engineering Research, vol. 39, no. 9, pp. 797-799, 2019.

[69] Y. K. Kyaw, E. L. Kuznetsova, A. V. Makarenko "Complex mathematical modelling of mechatronic modules of promising mobile objects," INCAS Bulletin, 12(Special Issue), pp. 91-98, 2020.

[70] L. E. Kuznetsova, V. G. Fedotenkov, "Dynamics of a spherical enclosure in a liquid during ultrasonic cavitation," Journal of Applied Engineering Science, 18(4), pp. $681-686,2020$.

[71] A. V. Makarenko, E. L. Kuznetsova, "Energy-Efficient Actuator for the Control System of Promising Vehicles," Russian Engineering Research, 39(9), pp. 776-779, 2019.

[72]E. L. Kuznetsova, A. V. Makarenko, "Mathematic simulation of energy-efficient power supply sources for mechatronic modules of promising mobile objects," Periodico Tche Quimica, 15 (Special Issue 1), pp. 330338, 2018.

[73] Y. Li, A. M. Arutiunian, E. L. Kuznetsova, G. V. Fedotenkov, "Method for solving plane unsteady contact problems for rigid stamp and elastic half-space with a cavity of arbitrary geometry and location," INCAS Bulletin, 12(Special Issue), pp. 99-113, 2020.

[74]E. L. Kuznetsova, G. V. Fedotenkov, E. I. Starovoitov, "Methods of diagnostic of pipe mechanical damage using functional analysis, neural networks and method of finite elements," INCAS Bulletin, 12(Special Issue), pp. 79-90, 2020.

[75] Y. K. Kyaw, P. F. Pronina, P. O. Polyakov, "Mathematical modelling of the effect of heat fluxes from external sources on the surface of spacecraft," Journal of Applied Engineering Science, 18(4), pp. 732-736, 2020.

\section{Creative Commons Attribution License 4.0 (Attribution 4.0 International, CC BY 4.0)}

This article is published under the terms of the Creative Commons Attribution License 4.0

https://creativecommons.org/licenses/by/4.0/deed.en_US 